\title{
Community stakeholders' perceptions of crime and victimization: A mixed-methods approach to understanding collective efficacy and social cohesion in the rural heartland
}

\author{
Ashley Lockwood \\ Department of Psychology \\ Fort Hays State University \\ Martin Allen 208 \\ 600 Park Street \\ Fort Hays, Kansas 67601 \\ April Terry \\ Department of Criminal Justice \\ Fort Hays State University \\ Rarick Hall 233J \\ 600 Park Street \\ Fort Hays, Kansas 67601
}

Contact information: Ashley Lockwood, 785628 4468; avlockwood@mail.fhsu.edu

\begin{abstract}
Previous criminological literature has mostly neglected rural communities, often treating these places as smaller pieces of urban culture. Literature suggests rural communities operate differently than urban neighborhoods, with distinctive values, norms, and community cohesion. For example, concepts surrounding collective efficacy may work counterproductively in rural areas - further exploiting outed community members within "close-knit" environments. The current study sought to compare perceptions of collective efficacy and social cohesion, crime, and victimization between rural and urban counties across one Midwestern rural state. Using a mixed-methods approach, community stakeholders from a variety of professions were surveyed. Quantitative results suggest similar perceptions of collective efficacy and social cohesion in rural and urban communities while qualitative responses paint a much different picture - an image of rural communities "minding their own business" and both formally and informally intervening only in the most extreme and personalized scenarios.
\end{abstract}

Keywords: rural, collective efficacy, social cohesion, victimization, crime 


\section{Introduction}

Rural communities in America are often characterized by white picket-fences, flourishing crops, and quaint small towns (Cromartie \& Bucholtz, 2008; U.S. Census Bureau, 2020). The term rural has been used to conceptualize small villages, unincorporated townships, or sometimes a unique worldview (Weisheit \& Donnermeyer, 2000). When asked to picture rural neighborhoods, individuals residing in urban areas likely picture open spaces, spanning fields (U.S. Census Bureau, 2020), and girls in white cotton dresses - the common description found in many country music songs. Basic perceptions of rural communities assume positive interactions between residents and a "love thy neighbor as thyself" mindset. In these rural communities, acquaintanceships are dense, and some community members (e.g., status worthy) live in a "close-knit" atmosphere (Terry, 2020), almost mimicking a unique family dynamic.

Unique aspects of rural environments remain neglected across nearly all academic disciplines. This oversight is a disservice to the field of criminology and ignores those residing in less-populated regions around the world. While most of the United States population resides within urban areas, most places in the U.S. could be classified as rural (U.S. Census Bureau, 2020). Donnermeyer (2015) discussed the difficulty of conceptualizing "rural," as rural scholarship in criminology has developed at a much slower pace than urban-focused work (Donnermeyer, 2015). Likewise, most seminal criminological theories paved their way in the field by utilizing urban samples (Donnermeyer et al., 2013) - many times, targeting the most extreme depictions of urbanization (e.g., overcrowding, social inequality, and racial oppression) (see Cobbina et al., 2008; Davis, 2007).

Donnermeyer and DeKeseredy (2008) suggest early social disorganization studies are limited because they assume crime in rural communities is due to a lack of cohesion and solidarity, rather than questioning whether there are various kinds of social and normative structures. Yet, over the past few decades, some traction for rural criminology has surfaced, further expanding scholarship on rural crime (see DeKeseredy et al., 2007; Donnermeyer, 2015; Donnermeyer \& DeKeseredy, 2014; Terry, 2020). Still, unique components and challenges specific to rural communities are ignored, and many of these rural areas are treated as "miniature versions of urban areas, with similar social processes occurring on a smaller scale" (Kaylen \& Pridemore, 2013, p. 170). With many scholars bypassing rural locations, an urban ethnocentrism in criminology is subsequently produced. 


\section{Literature Review}

\section{Rural Places}

Different sources, such as the U.S. Census Bureau and the U.S. Department of Agriculture, provide guidance for defining rurality based on population. For example, the United States Census Bureau uses a dichotomous definition for rural places being any geography not classified as urban. Urbanized areas have a population of 50,000 or more while urban clusters have a population of at least 2,500 and less than 50,000 (U.S. Census Bureau, 2020). A second model can be found using the U.S. Department of Agriculture's rural and urban continuum codes. This system sub-divides counties into three metropolitan (i.e, metro) and six non-metropolitan (i.e., non-metro) categories based on population density and proximity to more a densely populated county, and was most recently revised in 2013 (U.S. Department of Agriculture, 2020). While these measures define rural places differently, most scholars can loosely agree upon characteristics that describe rural communities.

Early studies have suggested U.S. rural communities hold many strengths over urban areas; yet, they are also known for less appealing features. It is difficult to refute rural communities and their connection to religious life, avoiding sin, (Willits et al., 1990), and presenting as a "closeknit" community (Terry, 2018; Terry, 2020). However, some argue rural communities are romanticized (Tickamyer \& Duncan, 1990) for positive aspects while, for some, these close-knit ties work to push outsiders further to the margins (Terry, 2019; Terry, 2020). Additionally, when U.S. rural communities display close insider ties, these same connections may decrease the chances that one intervenes, reports, or acts ethically within their professional roles (e.g., law enforcement) when responding to crime (Donnermeyer \& DeKeseredy, 2014). Power and discourse operate differently in rural communities, as outlined two decades ago in Liepens'(2000) work on rural studies. People, meanings, practices, and spaces and structures, influence social and cultural structures (Liepens, 2000) as they are more isolated from other communities, and exhibit marked suspicion of outsiders (Barnett \& Mencken, 2002; Weisheit \& Donnermeyer, 2000). A divide emerges between those included in the close-knit community and the outsiders (Terry, 2019; Terry, 2020). In communities where "everyone knows everyone's business," and reputations are at stake (Edwards et al., 2015), rural communities focus their attention on crime differently than urban communities (Terry, 2019; Terry, 2020).

\section{Social Disorganization}

Studies supporting how place influences criminal behavior have been around since at least the 1940s with Shaw and McKay's (1942) work on social disorganization theory. Some 40 years later, others have encouraged the consideration of additional variables. For example, Bursik (1988) argued the focus on crime and delinquency was dependent upon the ability of the 
community to regulate (Bursik, 1988) while introducing victimization into the equation. Shortly thereafter, Sampson and colleagues (1997) followed with the concept of collective efficacy, a term capturing social cohesion among neighbors and their combined willingness to intervene for the common good (Sampson et al., 1997). Rose and Clear (1998) focused on ethnic heterogeneity, stating communities were then more likely to include high mobility, which also meant less connection and formed bonds. In turn, fewer connections meant less trust and investment in the community, lower levels of informal social control, and reduced collective efficacy (Kingston et al., 2009; Steeinbeek \& Hipp, 2011). Rural communities may begin to develop their own distinct system of values shaped largely by social and spatial isolation and limits to outside resources (Borders \& Booth, 2007; Sampson \& Wilson, 1995). Many U.S. rural communities struggle with unique hardships (e.g., lack of access to services) and social environments (e.g., traditional values) compared to more populous locations (Terry, 2019; Terry, 2020).

\section{Collective Efficacy and Community Cohesion}

At the core, the concept of social disorganization assumes locations who display low levels of solidarity and cohesion have higher crime rates in comparison to those expressing the opposite (Sampson, 2012). In part, this concept is rooted in the idea of collective efficacy - an important component of social disorganization theories. According to Sampson et al., (1997) collective efficacy is, "social cohesion among neighbors combined with their willingness to intervene on behalf of a common good" (p. 918). The assumption is rural communities display greater levels of collective efficacy - a deepened desire to look out for one another with a "close-knit" feeling; thus, resulting in increased willingness to intervene, support one-another, and result in a decrease in crime. Still, recent literature points to continued victimization and other shortcomings present in rural communities (Terry, 2020).

Collective efficacy focuses on the collective nature of a community (Hipp, 2016), an important facet when considering the comparison between rural and urban locations. This component of social disorganization is described as a blend between social control and social cohesion (Armstrong et al., 2015), and has been referred to as "the glue that binds neighborhoods together" (Higgins \& Hunt, 2016, p. 1). Social cohesion describes the way community members feel about their neighborhood - are trust, safety, and common goals shared within the community? Communities with high levels of social cohesion are likely to exercise improved informal social control. Thus, crime in these neighborhoods is assumed to be lower due to the collective nature of residents. In contrast, the ideal held steadfast by many social sciences is that rural communities are crime free and full of "moral virtue" (Lockie, 2000, p. 20); yet, this statement is a myth. Despite common perceptions, crime and victimization in rural communities remains invasive even when high collective efficacy and social cohesion is present and appears to be greater than compared to their urban counterparts (see Terry, 2019; Terry, 2020). 


\section{The Current Study}

Rural communities often respond to crime differently than urban areas, with an increased emphasis placed on privacy, close social ties, and informal social controls (Websdale, 1998; Terry, 2018). Regardless of high levels of collective efficacy, social norms in these rural areas may dissuade individuals from reporting or reaching out to formal controls (Terry, 2019; Donnermeyer, 2015). Rather than contacting law enforcement or filing reports, individuals residing in non-urban areas often choose to handle interpersonal agreements on their own or choose not to report to maintain reputations (Edwards et al., 2015; Terry, 2020). Other times, those who lack family status choose not to report as they believe their rural communities will further out them, denying them assistance (Terry, 2019).

While Sampson and colleagues' (1997) seminal work points to the merit of survey research when examining urban collective efficacy, stating, "collective efficacy is a construct that can be measured reliably at the neighborhood level by means of survey research strategies" (p. 923), others have found qualitative analysis yields in-depth understanding of rural communities (see Terry, 2018, Terry, 2020). Qualitative statements paint a richer picture to explore individual perceptions of community, especially within non-urban locations. Thus, it was the goal of the current study to expound on previous limitations and provide new insights into rural culture. The study provides a mixed-methods approach to understanding the collective nature of rural communities within a rural Midwestern state. With previous literature in mind, the researchers of the current study developed three hypotheses:

1) Stakeholders in rural counties (frontier, densely-settled rural, and rural) would report similar levels of collective efficacy and social cohesion to stakeholders in urban counties (semiurban, urban).

2) Stakeholders in rural counties would report lower levels of perceived violence than stakeholders in urban counties.

3) Stakeholders in rural counties would report higher levels of victimization than stakeholders in urban counties.

\section{Method}

\section{Participants and Procedure}

Participants: The current study focused on community stakeholders residing in a Midwestern state located in the U.S. heartland. Specifically, individuals working in corrections, schools, churches, mental health, county extensions, courts, and law enforcement were targeted from all 105 counties. Community stakeholders were contacted from a pool of personal contacts 
held by the research team. Additional participants were recruited via email using contact information pulled from online resources to ensure at least one individual from the previously listed professions was contacted from each county. Within many rural communities, certain professionals (e.g., mental health providers) serviced multiple counties and were only asked to participate for one selected county, preferably focusing on the community of their personal residence. In total, 809 community members were emailed a SurveyMonkey link script and asked to participate in the survey. In total, 249 individuals responded to the survey, resulting in a $30.7 \%$ response rate. From here, data cleaning resulted in the removal of 14 participants resulting in a current sample including 235 participants ( 82 males, 149 females, 4 not indicated; Mage = 41.52, $S D=12.66)$.

Descriptive information for community professions can be found on Table 1 . Those working within the correctional field comprised the majority of participants $(38.3 \%)$, followed by school officials or staff $(11.1 \%)$, mental health providers $(7.7 \%)$, extension agents $(6.8 \%)$ and law enforcement $(6.8 \%)$, clergy $(6.4 \%)$, attorneys $(4.7 \%)$, and healthcare workers $(4.3 \%)$. The remaining community members $(13.6 \%)$ identified their employment as "other." The majority of the sample self-identified as Caucasian (94.5\%), followed by Hispanic (3.8\%), African American $(.9 \%)$, Asian/Pacific Islander (.4\%), and other (.4\%). The race/ethnicity percentages are consistent with the current state as approximately $86 \%$ of the state identifies as white (U.S. Census Bureau, 2019).

Table 1: Professions of Community Stakeholders

\begin{tabular}{lcc}
\hline Profession & $\mathrm{n}$ & percent \\
Corrections professionals & 90 & 38.3 \\
School officials/staff & 26 & 11.1 \\
Mental health providers & 18 & 7.7 \\
Extension agents & 16 & 6.8 \\
Law enforcement & 16 & 6.8 \\
Clergy & 15 & 6.4 \\
Attorneys & 11 & 4.7 \\
Healthcare workers & 10 & 4.3 \\
Other & 32 & 13.6 \\
\hline
\end{tabular}

Population classifications: Population classifications were broken down using the state's Department of Health and Environment Classifications (2018): frontier, rural, densely-settled rural, semi-urban, and urban to include even those most-rural places within the state. Of the 105 counties, the sample included community stakeholders from 71 counties, with the majority of stakeholders residing in densely-settled rural counties $(n=94)$, followed by rural $(n=38)$, urban $(n=46)$, frontier $(n=26)$ and semi-urban $(n=21)$. Densely-settled rural counties are the most 
common in the current state (Department of Health and Environment Classifications, 2018). Population descriptions used to make these classifications can be found on Table 2.

Table 2: County Classifications

\begin{tabular}{ll}
\hline Classification & Population Density \\
\hline Frontier & Less than $6.0 \mathrm{ppsm}$ \\
Rural & $6.0-19.9 \mathrm{ppsm}$ \\
Densely-settled Rural & $20.0-39.9 \mathrm{ppsm}$ \\
Semi-urban & $40.0-149.9 \mathrm{ppsm}$ \\
Urban & 150.0 or more ppsm \\
\hline
\end{tabular}

Note: ppsm = persons per square mile; classifications from the Department of Health and Environment (2019)

\section{Measures}

The current study utilized a mixed-methods approach including both quantitative survey analysis as well as open-ended qualitative responses. Following each scale, participants were provided guided questions to probe personal perceptions of crime, victimization, and response in their respective communities. A full list of instruments can be found in Appendix A.

Collective efficacy scale - adapted: With a rural focus, the current study acknowledges validation of the Collective Efficacy Scale (Sampson et al., 1997), and utilized it as a critical guide but adapted the questions $(\alpha=.86)^{1}$, to be more specific to a rural population. For example, rather than asking participants to report the number of times they witnessed a certain crime firsthand (or heard a gunshot, for example), the current schedule focused on one's simple awareness of crime in their community, as previous studies have found the overt nature of violent crime is different in rural areas than urban locations (see Terry, 2018).

The original Collective Efficacy Scale (Sampson et al., 1997) was designed to assess both collective efficacy and social cohesion and control among neighborhoods. Using a 5-point Likert scale ( $1=$ Very likely, $5=$ Very unlikely), participants were provided a series of statements and asked to indicate the level of agreement ( $1=$ Strongly disagree, $5=$ Strongly agree $)$ and the likelihood community individuals would intervene if each crime were to happen in their community. Negatively worded items were reverse-coded so high mean values indicated high collective efficacy. In the original development of this measure, both social cohesion and social control were found to be closely associated across neighborhoods. Thus, these two pieces of the scale are combined to create one measure of collective efficacy. An example qualitive question 
includes, "In a few sentences, please describe how you feel individuals in your community would respond to the above events" (related to specific identified crimes). ${ }^{1}$

Violence and Victimization measure - Adapted: Sampson and colleagues (1997) assessed violence within neighborhoods through three measures: violence, victimization, and actual homicide rates. Two of these measures were adapted and included within the current study. However, homicide rates were not included as serious violent offenses such as homicide are far less common in rural areas. For the current study, the violence measure was adapted to include additional criminal events known to occur more frequently in rural locations and were labeled as "crime" (see below).

Participants were asked to indicate how often a series of criminal events occurred within their neighborhood. The original measure included five crimes: a fight in which a weapon was used, a violent argument between neighbors, a gang fight, a sexual assault or rape, and robbery. For the current study, the measure was adapted to cater to crimes more frequently experienced in rural locations. This adapted version included a fight in which a weapon was used, a violent argument between neighbors, domestic violence, a sexual assault or rape, drug usage, and theft. An example qualitive question for this scale included, "While you have lived in this neighborhood, has anyone ever used violence, such as in a mugging, fighting, or sexual assault, against someone else in your town?"

\section{Results}

\section{Collective Efficacy \& Social Cohesion}

To test hypothesis one, a one-way between-subjects analysis of variance (ANOVA) was utilized to determine differences between reported collective efficacy between frontier, rural, densely-settled rural, semi-urban, and urban locations. The analysis was not significant, $F(4$, $195)=1.12, p=.35$. Community stakeholders from counties classified as frontier $(M=3.42, S D$ $=.66)$, rural $(M=3.36, S D=.56)$, densely-settled rural $(M=3.22, S D=.64)$, semi-urban $(M=3.37$, $S D=.61)$, and urban $(M=3.14, S D=.72)$ perceived similar levels of collective efficacy.

When open-coding qualitative responses, different professions noted the nature of closeknit communities, but some, as demonstrated below, believed their rural community worked against this mentality, such as this statement by a corrections professional from a densely-settled rural location: "The neighborhoods in my community vary considerably. Some are very close

\footnotetext{
${ }^{1}$ Cronbach's alpha $(\alpha)$ provides a measure of internal consistency, or how interrelated items on a scale are to one another (see Cronbach, 1951). Cronbach's alpha is expressed as a number between 0 to 1, with a reliability estimate closer to one indicating stronger interrelatedness of scale items.
} 
knit, law abiding, and empathetic, others are the opposite." Another observation from a corrections professional from a densely-settled rural location reinforces this view: "Our neighborhood isn't super close-knit so they might not be as likely to report something as others. I feel that they would be more likely to report violence than suspicious activity."

In other responses, many participants noted the disconnect between working together and fulfilling community needs, including comments respectively by a healthcare worker and an extension agent, both from a rural county: "Awareness and community collaboration to recognizing a need and working together to fill the gap." "We all need to work together to improve our communities among our county."

In traditional studies of a community's appearance, such as those based on Broken Windows Theory (James \& Kelling, 1982), the current study found the physical depiction of the area influenced the perception of crime, as several participants mentioned the need to make the community appear cleaner, as indicated by the short, to-the-point comments of a mental health provider in a densely-settled county and a school worker from a rural county: "Clean up streets. Trash."; "Cleaning up the town."

While quantitative results indicated little difference between rural and urban perceptions of community collective efficacy and cohesion, qualitative responses contradicted these results from a variety of working professionals. The current study found community patrons in rural areas may not be willing to intervene. unless directly impacted. For example, a professional from a frontier county commented: "I feel it truly depends on the person, however, overall most tend to mind their own business and would turn a blind eye." A corrections professional from a densely-settled rural county said essentially the same thing: "Sometimes they would try to do something, sometimes they have the 'it is their problem, not mine and I am not getting involved' attitude."

The quantitative and qualitative responses, all mirroring collective efficacy and social cohesion, contradict one another. While the survey scales found little difference between these measures when comparing rural and urban professionals, the qualitative responses are consistent with rural literature exposing differences in rural community members being willing to respond to crime-having a preference towards a "mind your own business" mentality.

\section{Crime and Victimization}

To test hypothesis two, a second one-way ANOVA was conducted to determine differences between levels of crime between the county classifications. Again, no significant difference was found between the five county classifications on the violence measure, $F(4,165)=.27, p=.89$. 
Individuals from counties classified as frontier $(M=.38, S D=.46)$, rural $(M=4.07, S D=7.85)$, densely-settled rural $(M=4.70, S D=26.26)$, semi-urban $(M=2.29, S D=7.29)$, and urban $(M=$ $4.24, S D=14.84)$ reported similarly perceived crime rates in their locations.

Last, a final one-way ANOVA was conducted to study hypothesis three, examining differences in victimization. Community stakeholders from frontier $(M=1.92, S D=.28)$, rural $(M=1.97, S D=.18)$, densely-settled rural $(M=1.83, S D=.38)$, semi-urban $(M=1.88, S D=.33)$ and urban $(M=1.91, S D=.29)$ counties indicated similar amounts of personal victimization. Thus, no significant difference was found between the five county classifications, $F(4,182)=$ $1.18, p=.32$.

Although counties were similar in their reporting of crime and violence, again, qualitative responses suggest this may be due to different informal social control mechanismssystems that dictate which crimes are reported. Generally speaking, participants felt a sense of detachment, believing only publicly known and observed acts were worthy of reporting. As an educator from a densely-settled rural county observed: "I think the only thing most people in my community would do is call the police. No one wants to get involved in 'other people's business." An attorney from a densely-settled rural county likewise felt that "If the events were a public disturbance, I feel individuals would intervene. If they believe the issue is 'none of their business', they would not."

Perhaps, people from rural places focus on the degree of seriousness of crimes suggesting rural residents are not prone to report crime unless it is "extreme" in nature. Numerous participants agreed with this sentiment, that community citizens only report crime if the behavior meets the criteria of "serious" violence. "Seems like people in our neighborhood generally keep to themselves. Only in the most extreme of circumstances would they interfere on someone's behalf.", said a professional from a densely-settled rural county. This comment was echoed by a professional from a frontier county who observed that "Most people here would help their neighbors if they saw trouble. The flip side of this is we often look the other way if it isn't directly endangering someone."

\section{An Unexpected Finding}

The current study sought to examine perceptions of collective efficacy and cohesion along with perceived and actual victimization rates in their respective communities. Qualitative findings uncovered an unpredicted, but theoretically-grounded discovery - several participants expanded upon the role of living in the "country." Those residing outside of city-boundaries referenced their own sense of justice and community, such a corrections professional from a densely-settled rural county who claimed: "First of all, I live in the country so the above questions don't really represent my 'neighborhood.' From a rural county comes a similar 
comment: "I live in the country. We all look out for each other and make contact if we notice anything not quite right." This mentality even held true for so-called "country" folk not residing around rural-based counties, as is demonstrated by the extension agent residing within a semiurban county below: "You're probably wanting responses from people in town...but in the country, we would take care of things. If it is by my house, the neighbors and I will take care of it." The above findings suggest citizens residing within the county, not city limits, see themselves as outside the bounds of city policies and procedures - demanding a need for their own version of crime and punishment.

\section{Discussion}

\section{Purpose and Summary of Findings}

The purpose of the current study was to provide a comparison between rural and urban places within one predominately U.S. rural state, with a focus on collective efficacy and social cohesion. The comparison was based on the responses from a sample of community stakeholders. Together, the quantitative findings from the current study suggest levels of collective efficacy and social cohesion may not differ as greatly as outlined by some previous literature. Yet, qualitative responses tell a different tale. Thus, the first hypothesis of the current study was partially supported. Quantitative measures of collective efficacy revealed no significant differences between rural and more urban locations. However, qualitative responses outline unique challenges present in rural communities.

Sampson and colleague's (1997) original quantitative measure of collective efficacy, violence, and victimization is widely recognized and has been shown to be an accurate picture of what is occurring within urban locations, not rural locations. When substituting some questions related to the prevalence of crimes occurring in both urban and rural locations, the collective efficacy score was evened, and the crime measures did not significantly differ. Rates of perceived crime appear relatively synonymous between rural and urban places, perhaps discounting the myth that rural places remain crime free and cohesive, and failing to support hypothesis two. No significant differences were found between levels of personal or community victimization among stakeholders from each of the county classifications, failing to support the third hypothesis of the study.

\section{Limitations}

While the study produced unexpected, yet interesting findings, the current research is not without limitations. First, although comparable sample sizes were surveyed from many of the county classifications, some group sizes were smaller than was ideal and the densely-settled rural category was more than double the other classifications. It is possible the overabundance of 
corrections-focused individuals resulted in a somewhat tainted view of crime and victimization. Second, limited qualitative responses provide only a glimpse of the experiences of those residing in both rural and urban locations within the Midwestern state. While the information gleaned from this data is rich with detail, responses included in the paper are not comprehensive and provide only a snapshot of these unique issues. The current study is only a piece of a larger-scale project examining other forms of stigma, oppression, and victimization within rural communities.

\section{Implications and Conclusion}

Criminological literature has historically focused on urbanized areas - assuming all communities operate similarly, including rural locations. Yet, the past several decades of rural criminological literature has challenged this generalization, pointing out how rural communities operate differently (Donnermeyer, 2015), harboring unique traditional values and beliefs, and working diligently to appear as a "close-knit" harmonious community, but not necessarily one that reduces all types of crime (Terry, 2018, Terry, 2020). With the recent additions to the rural literature, the current study sought to further understand community collective efficacy and social cohesion, along with perceptions of crime and victimization by diverse professions across one Midwestern rural state.

The results of the current study produced an interesting set of results related to methodological considerations when conducting rural research. Specifically, quantitative data analysis suggested community stakeholders in rural and urban areas hold similar perceptions about the collective nature of their hometowns - contradicting recent literature on rural areas. However, qualitative responses by this same set of participants further yielded analysis representing a different community atmosphere - one where patrons in rural communities are not likely to intervene to help one another unless the crime is serious in nature. Yet, in counterdistinction, rural members seek to clean up their neighborhoods and encourage everyone to work together. While this was stated numerous times, previous studies question if everyone in a rural community is allowed a seat at the table (see Terry, 2018).

Given the current findings, future studies should heavily expand upon the qualitative nature of understanding rural dynamics. This could include open-ended survey probes similar to the current study or even expand to include focus groups or community interviews. Such findings can help better understand barriers preventing rural communities from increasing community engagement, including all interested citizens, with a focus on crime prevention and intervention. Additionally, those residing in county, but not city lines, feel they reside outside the purview of formal reporting and intervening. They indicate a "we take care of our own business" mentality that occurs without the need of those residing within city lines. This finding is interesting and 
quite telling of the extreme depictions of rural areas and people residing in such places within the United States.

\section{References}

Armstrong, T. A., Katz, C. M., \& Schnebly, S. M. (2015). The relationship between citizen perceptions of collective efficacy and neighborhood violent crime. Crime and Delinquency, 61(1), 121-142. https://doi.org/10.1177/0011128710386202

Barnett, C., \& Mencken, F. C. (2002). Social disorganization theory and the contextual nature of crime in nonmetropolitan counties. Rural Sociology, 67(3), 372-393. https://doi.org/10.1111/j.1549-0831.2002.tb00109.x

Borders, T. F., \& Booth, B. M. (2007). Research on rural residence and access to drug abuse services: Where are we and where do we go? Journal of Rural Health, 23, 79-83. https://doi.org/10.1111/j.1748-0361.2007.00128.x

Bursik, R. J. (1988). Social disorganization and theories of crime and delinquency: Problems and prospects. Criminology, 26(4), 519-552. https://doi.org/10.1111/j.1745-

9125.1988.tb00854.x

Cobbina, J., Miller, J., \& Brunson, R. (2008). Gender, neighborhood danger and risk avoidance strategies among urban African American youth. Criminology, 46(3), 501-538. https://doi.org/10.1111/j.1745-9125.2008.00122.x

Cromartie, J., \& Bucholtz, S. (2008, June). Defining the "rural" in rural America. Amber Waves, $6(3)$, pp. 29-24.

Cronbach, L. J. (1951). Coefficient alpha and the internal structure of test. Pschometrika, 16(3), 297-334. https://doi.org/10.1007/BF02310555

Davis, C. P. (2007). At-risk girls and delinquency: Career pathways. Crime \& Delinquency, 53(3), 408-435. https://doi.org/10.1177/0011128707301626

DeKeseredy, W., Donnermeyer, J. F., Schwartz, M. D., Tunnell, K. D., \& Hall, M. (2007). Thinking critically about rural gender relations: Toward a rural masculinity crisis/male peer support model of separation/divorce sexual assault. Critical Criminology, 15(4), 295-311. https://doi.org/10.1007/s10612-007-9038-0 
Donnermeyer, J.F. (2015). The social organisation of the rural and crime in the United States: Conceptual considerations. Journal of Rural Studies, 39, 160-170. https://doi.org/10.1016/j.jrurstud.2014.11.014

Donnermeyer, J. F., \& DeKeseredy, W. (2008). Toward a rural critical criminology. Southern Rural Criminology, 23(2), 4-28.

Donnermeyer, J. F., \& DeKeseredy, W. (2014). Rural criminology. Routledge. https://doi.org/10.4324/9780203094518

Donnermeyer, J., Scott, J., \& Barclay, E. (2013). How rural criminology informs critical thinking in criminology. International Journal for Crime, Justice and Social Democracy, 2(3), 6991. https://doi.org/10.5204/ijcjsd.v2i3.122

Edwards, K. M., Rodenhizer-Stämpfli, K. A., \& Eckstein, R. P. (2015). Bystander action in situations of dating and sexual aggression: A mixed methodological study of high school youth. Journal of Youth and Adolescence, 44(12), 2321-2336. https://doi.org/10.1007/s10964-015-0307-z

Higgins, B. R., \& Hunt, J. (2016). Collective efficacy: Taking action to improve neighborhoods. NIJ Journal, 277, 18-21. Retrieved from https://www.ncjrs.gov/pdffiles1/nij/249823.pdf

Hipp, J. R. (2016). Collective efficacy: How is it conceptualized, how is it measured, and does it really matter for understanding perceived neighborhood crime and disorder? Journal of Criminal Justice, 46, 32-44. https://doi.org/10.1016/j.jcrimjus.2016.02.016

James, W. Q., \& Kelling, G.L. (1982). Broken windows. Atlantic Monthly, 249(3), 29-38.

Kansas Department of Health and Environment (2018). Annual summary of vital statistics, Kansas 2018. Retrieved from https://www.kdheks.gov/phi/as/2018/2018_Annual_Summary.pdf

Kaylen, M. T., \& Pridemore, W. A. (2013). The association between social disorganization and rural violence is sensitive to the measurement of the dependent variable. Criminal Justice Review, 38(2), 169-189. https://doi.org/10.1177/0734016813476715

Kingston, B., Huizinga, D., \& Elliot, D. S. (2009). A test of social disorganization theory in high-risk urban neighborhoods. Youth and Society, 41(1), 53-79. https://doi.org/10.1177/0044118X09338343 
Liepens, R. (2000). New energies for an old idea: Reworking approaches to 'community' in contemporary rural studies. Journal of Rural Studies, 16(1), 23-35.

https://doi.org/10.1016/S0743-0167(99)00042-X

Lockie, S. (2000). Crisis and conflict: Shifting discourses of rural and regional Australia. Land of discontent: The dynamics of change in rural and regional Australia, 14, 32.

Rose, D. R., \& Clear, T. R. (1998). Incarceration, social capital, and crime: Implications for social disorganization theory. Criminology, 36(3), 441-479. https://doi.org/10.1111/j.1745-9125.1998.tb01255.x

Sampson, R. (2012). Great American City: Chicago and the Enduring Neighborhood Effect. University of Chicago Press. https://doi.org/10.7208/chicago/9780226733883.001.0001

Sampson, R. J., Raudenbush, S. W., \& Earls, F. (1997). Neighborhoods and violent crime: A multilevel study of collective efficacy. Science, 277, 918-924. https://doi.org/10.1126/science.277.5328.918

Sampson, R. J., \& Wilson, W. J. (1995). Toward a theory of race, crime, and urban inequality. In S.L. Gabbidon \& H.T. Green (Eds.), Race, Crime, and Justice: A Reader (pp. 177-190). Routledge.

Shaw, C., \& McKay, H. (1942). Juvenile delinquency in urban areas. University of Chicago Press. https://doi.org/10.2307/1334446

Steeinbeek, W., \& Hipp, J. R. (2011). Disorganization theory: Feedback effects among cohesion, social control, and disorder. Criminology, 49(3), 833-871. https://doi.org/10.1111/j.17459125.2011.00241.x

Terry, A. N. (2020). The architecture of rural life: The dangers of dense collective efficacy for at-risk girls. Rural Sociology, 85(3), 780-805. https://doi.org/10.1111/ruso.12325

Terry, A. N. (2018). Dirt roads to justice and heartland girls: Coercive sexual environments in non-metropolitan communities (Doctoral dissertation).

Terry, A. N., \& Williams, S. L. (2019). On the outside looking in: Rural girls, trauma, and involvement in the criminal justice system. Journal of Aggression, Maltreatment, \& Trauma, 1-21. https://doi.org/10.1080/10926771.2019.1652218 
Tickamyer, A. R., \& Duncan, C. M. (1990). Poverty and opportunity structure in rural America. Annual Review of Sociology, 16(1), 67-86.

https://doi.org/10.1146/annurev.so.16.080190.000435

United States Department of Agriculture: Economic Research Service. (2020). Rural-urban continuum codes. Retrieved from https://www.ers.usda.gov/data-products/rural-urbancontinuum-codes/documentation/

U.S. Census Bureau. (2019). Quick Facts. Retrieved on April 28, 2020 from https://www.census.gov/quickfacts/KS

U.S. Census Bureau. (2020). Rural America. Retrieved from https://gisportal.data.census.gov/arcgis/apps/MapSeries/index.html?appid=7a41374f6b03456e9d13 $\underline{8 \mathrm{cb} 014711 \mathrm{e} 01}$

Websdale, N. (1998). Rural woman battering and the justice system: An ethnography. Sage Publications.

Weisheit, R. A., \& Donnermeyer, J. F. (2000). Change and continuity in crime in rural America. Criminal Justice, 1, 309-357.

Willits, F. K., Bealer, R. C., \& Timbers, V. L. (1990). Popular images of "rurality": Data from a Pennsylvania survey. Rural Sociology, 55(4), 559-578. https://doi.org/10.1111/j.15490831.1990.tb00697.x 
Appendix A.

\section{Collective Efficacy Measure - Social Cohesion and Trust}

(Sampson, Raudenbush, \& Earls, 1997)

How strongly do you agree...

People around here are willing to help their neighbors?

1 - strongly disagree

2 - somewhat disagree

3 - neutral

4 -somewhat agree

5 strongly agree

This is a close-knit neighborhood?

1 - strongly disagree

2 - somewhat disagree

3 - neutral

4 -somewhat agree

5 strongly agree

People in this neighborhood can be trusted?

1 - strongly disagree

2 - somewhat disagree

3 - neutral

4 -somewhat agree

5 strongly agree

People in this neighborhood generally don't get along with each other? (reverse code)

1 - strongly disagree

2 - somewhat disagree

3 - neutral

4 -somewhat agree

5 strongly agree

People in this town do not share the same values? (reverse code)

1 - strongly disagree

2 - somewhat disagree

3 - neutral

4-somewhat agree

5 strongly agree 
The following are a list of things that might happen in your neighborhood. After reading each one, please tell me how likely it is one of your neighbors would do something about it:

1. If someone was trying to break into a house.

1 - Very unlikely

2 - Somewhat unlikely

3 - Neither unlikely nor likely

4 - Somewhat likely

5 - Very Likely

2. If someone was illegally parking in the street.

1 - Very unlikely

2 - Somewhat unlikely

3 - Neither unlikely nor likely

4 - Somewhat likely

5 - Very Likely

3. If suspicious people were hanging around the neighborhood.

1 - Very unlikely

2 - Somewhat unlikely

3 - Neither unlikely nor likely

4 - Somewhat likely

5 - Very Likely

4. If people were having a loud argument in the street.

1 - Very unlikely

2 - Somewhat unlikely

3 - Neither unlikely nor likely

4 - Somewhat likely

5 - Very Likely

5. If a group of underage kids were drinking.

1 - Very unlikely

2 - Somewhat unlikely

3 - Neither unlikely nor likely

4 - Somewhat likely

5 - Very Likely

6. If some children were spray-painting graffiti on a local-building.

1 - Very unlikely

2 - Somewhat unlikely

3 - Neither unlikely nor likely

4 - Somewhat likely

5 - Very Likely

7. If there was a fight in front of your house and someone was being beaten or threatened.

1 - Very unlikely

2 - Somewhat unlikely

3 - Neither unlikely nor likely

4 - Somewhat likely

5 - Very Likely 
8. If a child was showing disrespect to an adult.

1 - Very unlikely

2 - Somewhat unlikely

3 - Neither unlikely nor likely

4 - Somewhat likely

5 - Very Likely

9. If a group of neighborhood children were skipping school and hanging out on a street corner.

1 - Very unlikely

2 - Somewhat unlikely

3 - Neither unlikely nor likely

4 - Somewhat likely

5 - Very Likely

10. If someone on your block was playing loud music.

1 - Very unlikely

2 - Somewhat unlikely

3 - Neither unlikely nor likely

4 - Somewhat likely

5 - Very Likely

11. If someone on your block was firing a gun.

1 - Very unlikely

2 - Somewhat unlikely

3 - Neither unlikely nor likely

4 - Somewhat likely

5 - Very Likely

12. If drugs were being sold on your block.

1 - Very unlikely

2 - Somewhat unlikely

3 - Neither unlikely nor likely

4 - Somewhat likely

5 - Very Likely

13. In a few sentences, please describe how you feel individuals in your community would respond to the above events. 


\section{Violence \& Victimization Measures}

How many times have you heard of the following occurring in the last 6 months in your neighborhood?

A fight in which a weapon was used.

A violent dispute between neighbors.

Domestic violence

A sexual assault or rape.

Drug usage

Theft

While you have lived in this town, has anyone ever used violence, such as in a mugging, fight, or sexual assault, against you or any member of your household?

While you have lived in this neighborhood, has anyone ever used violence, such as in a mugging, fight, or sexual assault, against someone else in your town?

\section{Most Pressing Issue}

After reading and answering the previous questions, think of the most pressing need in your community. What is it? With the issue you identified just now, what do you think is the most important first step in making a change? 